ARTICLE

\title{
Thermochemical anomalies in the upper mantle control Gakkel Ridge accretion
}

\author{
John M. O'Connor (10) 1,2,3凶, Wilfried Jokat (10) ${ }^{2,4}$, Peter J. Michael (10 ${ }^{5}$, Mechita C. Schmidt-Aursch (1) ${ }^{2}$, \\ Daniel P. Miggins ${ }^{6} \&$ Anthony A. P. Koppers (1) ${ }^{6}$
}

Despite progress in understanding seafloor accretion at ultraslow spreading ridges, the ultimate driving force is still unknown. Here we use ${ }^{40} \mathrm{Ar} /{ }^{39} \mathrm{Ar}$ isotopic dating of mid-ocean ridge basalts recovered at variable distances from the axis of the Gakkel Ridge to provide new constraints on the spatial and temporal distribution of volcanic eruptions at various sections of an ultraslow spreading ridge. Our age data show that magmatic-dominated sections of the Gakkel Ridge spread at a steady rate of $\sim 11.1 \pm 0.9 \mathrm{~mm} / \mathrm{yr}$ whereas amagmatic sections have a more widely distributed melt supply yielding ambiguous spreading rate information. These variations in spreading rate and crustal accretion correlate with locations of hotter thermochemical anomalies in the asthenosphere beneath the ridge. We conclude therefore that seafloor generation in ultra-slow spreading centres broadly reflects the distribution of thermochemical anomalies in the upper mantle.

\footnotetext{
${ }^{1}$ GeoZentrum Nordbayern, University Erlangen-Nürnberg, Schlossgarten 5, 91054 Erlangen, Germany. ${ }^{2}$ Alfred Wegener Institute Helmholtz Centre for Polar and Marine Research, Am Handelshafen 12, 27570 Bremerhaven, Germany. ${ }^{3}$ Faculty of Science, Vrije Universiteit Amsterdam, De Boelelaan 1085,1081 HV Amsterdam, Netherlands. ${ }^{4}$ University of Bremen, Fachbereich 5 - Geosciences, 28359 Bremen, Germany. ${ }^{5}$ College of Engineering \& Natural Sciences, University of Tulsa, Tulsa, OK 74104, USA. ${ }^{6}$ College of Earth, Ocean, and Atmospheric Sciences, Oregon State University, Corvallis, OR 97331-5503, USA. 凶email: j.m.oconnor@vu.nl
} 
S olving questions about the relation between the Earth's lithospheric plates and the asthenosphere is crucial for a more advanced understanding of mantle convection processes and how they might be directly, or indirectly, related to plate tectonics. Although the Gakkel Ridge extends for $1800 \mathrm{~km}$ under the Arctic sea ice it is nevertheless an ideal place to address these questions because it contains no significant transform offsets that offer a barrier to mantle flow ${ }^{1}$. In 2001 a high-resolution mapping and rock sampling study of Gakkel Ridge was accomplished during the international AMORE ice-breaker cruise to the high Arctic and North Pole ${ }^{1}$. Before this expedition, it was predicted-based on extrapolations from slow- to fast-spreading ridges-that ultraslow spreading would produce sparse volcanism, thinner crust, and very little hydrothermal activity, and low extents of melting of the underlying mantle ${ }^{1}$.

However, the findings from the AMORE cruise contradicted some of these predictions by showing that hydrothermal activity is far more abundant and that the ridge can be divided into two 'magmatism dominated' western (WVZ) and eastern (EVZ) zones separated by a 'sparsely magmatic zone' (SMZ) $)^{1,2}$ (Fig. 1). Moreover, the oceanic crust is highly variable with thick crust below the magmatic transverse ridges and thin crust in between in the more amagmatic zones 2,3 . Crucially, if the spreading rate decreases systematically along the Gakkel Ridge from $\sim 13 \mathrm{~mm} / \mathrm{yr}$ in the west to only $\sim 6 \mathrm{~mm} / \mathrm{yr}$ in the east at $120^{\circ} \mathrm{E}^{4-6}$, then the prediction of a global relationship between spreading rate and crustal thickness is no longer valid at ultraslow spreading rates. In this context, the formation of separate individual magmatic and amagmatic segments at ultraslow ridges is an important discovery, yet their origin cannot be explained by (local) differences in the rate of seafloor spreading and plate motion ${ }^{1,2,7}$.

Thus far, the lack of precise age dating on young $(<5 \mathrm{Ma})$ oceanic crust prevents any detailed understanding of such processes along mid-ocean ridges. Our study is a first attempt to shed

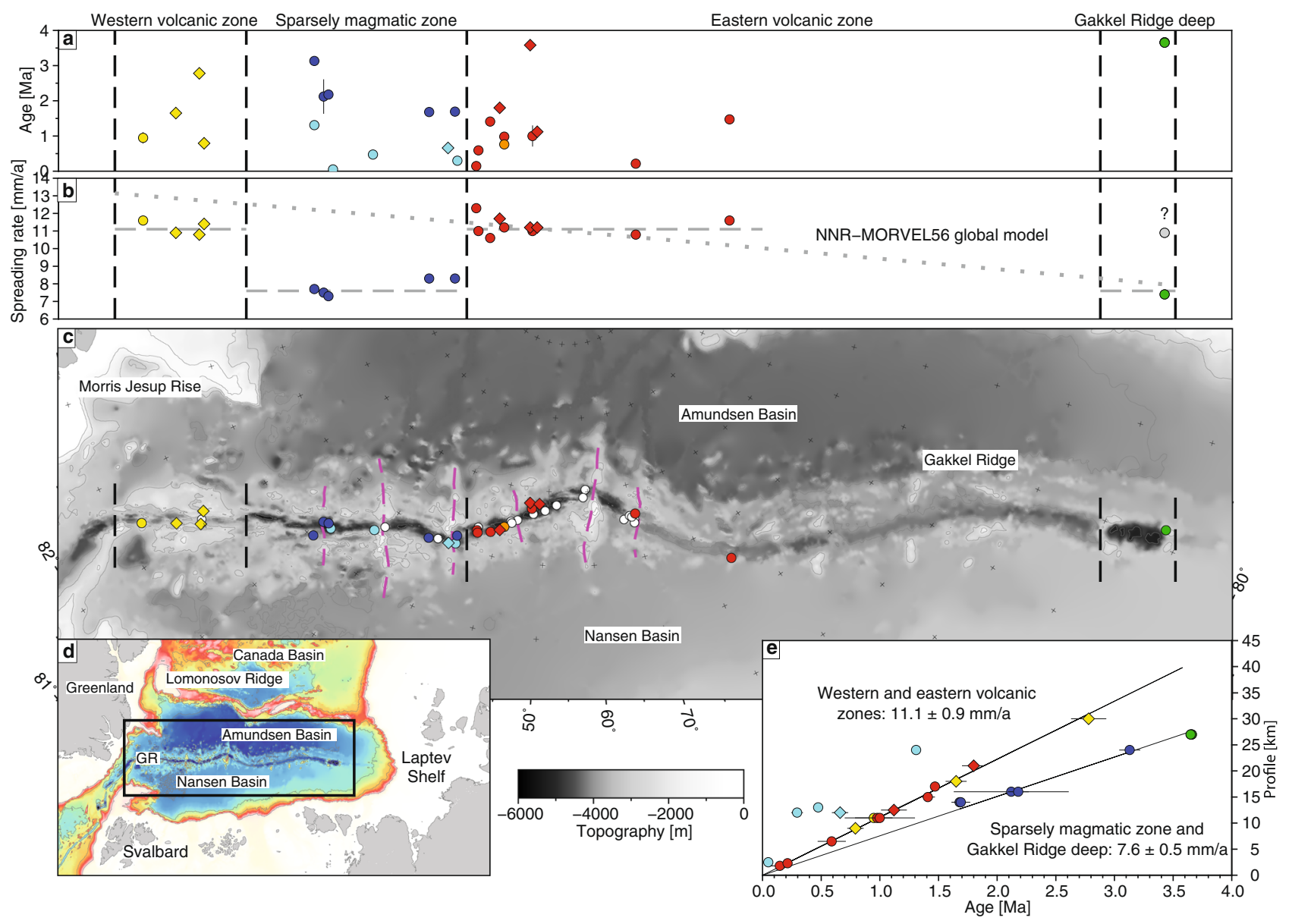

Fig. 1 Relation between spreading rate and magmatism along the Gakkel Ridge. All panels refer to Table 1 and Figs. 2-5. Yellow, blue, red and green symbols represent samples with reliable spreading rates. Light blue symbols are for samples that do not yield realistic spreading rates due to their mode of emplacement. The orange dot marks a sample without a profile. The diamond symbols are for samples with dates that fail on the data quality criteria discussed in the 'Methods' section. Error bars for age data are $2 \sigma$ uncertainty. Black dashed lines mark the boundaries of the different volcanic regimes. a Distribution of isotopic ages along Gakkel Ridge $\mathbf{b}$ Distribution of calculated spreading rates along the ridge. The question mark and open symbol are for an inferred 'fast' spreading rate at the eastern end of the GRD. The 'slow' spreading rate estimated for the eastern end of the GRD corresponds to the abrupt narrowing of the rift valley extending into the Laptev Sea. Thus, the 'slow' spreading rate calculated for the eastern end of the GRD likely continues to the east. The dotted line is for average spreading rates for the past 3 Ma calculated with the NNR-MORVEL56 global model ${ }^{8}$. c Topography of the Gakkel Ridge $^{56}$ and the distribution of dated samples along the ridge. Smaller white dots are for samples that did not yield ages. Pink dashed lines are for welldefined centres of focussed magmatism ${ }^{10}$. d Map of the study area, GR; Gakkel Ridge. e Average spreading rates calculated using the combined agedistance profiles. A robust linear regression (forced through the origin) yields an average spreading rate of $11.1 \pm 0.9 \mathrm{~mm} / \mathrm{yr}$ for the WMZ and EVZ. A poorly constrained rate of $7.6 \pm 0.5 \mathrm{~mm} / \mathrm{yr}$ is inferred for four SMZ and a single GRD-LS sample whereas the other SMZ samples do not predict a consistent spreading rate. An average of all the SMZ data, excluding the sample that does not meet all the data quality criteria, also yields a slow rate $(8.1 \mathrm{~mm} / \mathrm{yr})$. Note that in some cases samples with large errors overlap high-precision data. This figure was created with $\mathrm{GMT}^{57}$. 
more light on these questions by reporting on a systematic ${ }^{40} \mathrm{Ar} /$ ${ }^{39} \mathrm{Ar}$ dating study along the ultraslow spreading Gakkel Ridge. In doing so, we aim to test the fundamental assumption based on aeromagnetic data that spreading rates decrease systematically from $\sim 13$ to $\sim 6 \mathrm{~mm} / \mathrm{yr}$ along this mid-ocean ridge. This is essential because thus far only aeromagnetic data have been collected along the Gakkel Ridge due to ice coverage. Flight lines that are typically acquired at several hundred metres altitude and spaced around $18 \mathrm{~km}$ apart cannot resolve small magnetic anomalies, particularly those related to very young ages ${ }^{6}$. Arctic kinematic age models based on aeromagnetic data, therefore, are interpolated, tending to smooth out differences in spreading rate and type, and they do not provide reliable identification of anomalies younger than Chron $5(<10 \mathrm{Ma})$. Barring any presence of these artefacts, modern global models of seafloor spreading rates such as NNR-MORVEL5 $6^{8}$ provide the best estimate of spreading rates along the Gakkel Ridge (Fig. 1).

Here, we present evidence that other drivers-such as the thermal and chemical structure of the underlying mantle-may control the development of the two endmember-type magmatic and amagmatic spreading segments $1,3,7,9$ and that advances our understanding of the processes controlling ultraslow spreading on a global scale.

\section{Results}

${ }^{40} \mathrm{Ar} /{ }^{39} \mathrm{Ar}$ isotopic dating. Here we report the first extensive ${ }^{40} \mathrm{Ar} /{ }^{39} \mathrm{Ar}$ dataset that can robustly measure spreading rates along spreading centres, even along an ultraslow spreading ridge. To this end, we have drawn on recent advances in high-resolution multi-collector mass spectrometry to measure ${ }^{40} \mathrm{Ar} /{ }^{9} \mathrm{Ar}$ isotopic dates for young low-potassium basalt samples dredged from the Gakkel Ridge during the AMORE cruises in 2001 (Fig. 1). The results of twenty-five ${ }^{40} \mathrm{Ar} /{ }^{39} \mathrm{Ar}$ incremental heating dates for acid-leached basaltic groundmass are summarised in Table 1 and Supplementary Table 1 and Supplementary Dataset 1. Full analytical results are available in Supplementary Dataset 2. The criteria for assessing the quality of the age data are discussed in the 'Methods' section. Seven samples do not meet one or both of the criteria that a plateau consists of at least $50 \%{ }^{39} \mathrm{Ar}$ and a $P$-value $>5 \%$ (Table 1 and Fig. 1). These seven samples therefore cannot be considered robust but rather approximate age estimates.

Spreading rate calculation. We have used the isotopic dates to define a range of age profiles across the Gakkel Ridge rift valley between the present day and 3.7 Ma (Fig. 1 and Table 1). Individual age-distance profiles across the ridge and calculated spreading rates are shown in Figs. 2-5. The various sources of uncertainty in dredge-sampling an ultraslow spreading ridge are considered in the 'Methods' section. We can minimise this dredging uncertainty by stacking multiple age-distance profiles when calculating average spreading rates for the different segments of the ridge (Fig. 1). We argue that, notwithstanding the various assumptions and sources of uncertainty ('Methods' section), the ${ }^{40} \mathrm{Ar} /{ }^{39} \mathrm{Ar}$ dates provide high-precision constraint on spreading rates along the magmatic $\mathrm{WVZ}$ and $\mathrm{EVZ}$ sections of the ridge: $11 \pm 0.9 \mathrm{~mm} / \mathrm{yr}(n=15)$ (Fig. 1$)$. In contrast, the ${ }^{40} \mathrm{Ar} /$ ${ }^{39} \mathrm{Ar}$ dates for the SMZ and Gakkel Ridge Deep (GRD)-Laptev Sea (LS $)^{10}$ group at faster and slower spreading rates, respectively, rather than falling along a single spreading rate (Fig. 1). Four SMZ and a single Gakkel Ridge Deep (GRD) sample predict a poorly constrained slower spreading rate: $7.6 \pm 0.5 \mathrm{~mm} / \mathrm{yr}(n=7)$ (Fig. 1). The other SMZ dated samples predicting un-realistically fast-spreading rates were dredged from near the base of the rift valley wall (Fig. 3) suggesting there is significant off-axis magmatism (half the dated samples). This age distribution is consistent with a wider zone of accretion rather than a slower spreading rate. The 'apparent' spreading rate for samples erupted on-axis would be slower because it will take longer for lavas erupted on-axis to move off-axis if spreading is accommodated over a wider zone. The same could be true for the GRD, which is based on a single dated sample. However, regressing all the SMZ age data, except for one sample that does not meet all data quality criteria (Table 1$)$ also yields a slower spreading rate $(8.1 \mathrm{~mm} / \mathrm{yr})$ compared to the WVZ and EVZ so it cannot be excluded that these dates might belong to two different groups. Moreover, none of the dates lies in the vicinity of the WVZ/EVZ regression, even when considering the error bars. Thus, while we cannot link the slower SMZ-GRD trend necessarily to plate separation, it may well prove to be significant for understanding amagmatic crustal accretion.

Variation in spreading rate. In the case of the Gakkel Ridge, we are observing a consistent spreading rate in the magmatic WVZ and EVZ segments (Fig. 1). A lack of transform faults along the Gakkel Ridge is well-documented ${ }^{1}$ and is in accord with steady $\sim 11 \mathrm{~mm} / \mathrm{yr}$ spreading rates along most of the ridge (Fig. 1). Nevertheless, if we define the spreading rate as the plate separation rate, then it cannot vary (in terms of degrees of rotation about a pole) along the ridge as this would violate the geometric tenets of rigid plate tectonics. Therefore, differing spreading rates - such as the poorly constrained $\sim 7.6 \mathrm{~mm} / \mathrm{yr}$ rate we infer for the SMZ - can only be a young and unstable process. Otherwise, we would expect to observe large offsets between segments. This raises the possibility of another form of tectonic dislocation and/ or differences in the magmatic evolution in amagmatic segments.

For example, the SMZ dates might reflect a different style of lithospheric/crustal accretion. This notion is consistent with evidence from axial volcanic ridge morphology and abyssal hill patterns suggesting this cyclic process is the normal mode of development of axial parts of slow ${ }^{11,12}$ and ultraslow ridges ${ }^{13}$. In the WVZ, this process is evident from the transport of midAtlantic type elongate volcanic ridges away from the rift zone, e.g., refs. 1,2 (Fig. 2). In the EVZ, larger and slightly more magmatic edifices are dismembered, with basalts dominating the seafloor in between ${ }^{1,2}$ (Fig. 4). As a result, when calculating the WVZ and EVZ spreading rates we are using dated samples that have been dredged from magmatic structures that have been fragmented apart and transported away as the seafloor spreads from the active central rift axis. Because of this style of discontinuous volcanism, it is possible to measure the spreading rate based on the rifting of discreet volcanoes and ridges that have been erupted in the rift valley (see 'Methods' section for specific examples).

In contrast, seafloor spreading in the SMZ involves very little axial volcanism and is likely to be mostly amagmatic, with fresh mantle peridotites emplaced directly on the seafloor at the spreading axis ${ }^{1}$ (Fig. 3). Five of the 10 dates reported for the SMZ give anomalously young ages for their location in the rift valley (Fig. 3). Samples PS59 311-2 (Profile 10; 661 $\pm 68 \mathrm{ka}$ ) and PS59 310-001-1 (295 $\pm 53 \mathrm{ka})$ are located near the base of the rift valley wall where the rift valley bisects a transverse volcanic basement ridge $^{1,2,10}$ (Fig. 3). Sample PS59/252-1 (Profile 8; $474 \pm 30 \mathrm{ka}$ ) is located near the rift valley wall on the southern flank of a large volcanic centre that is less rifted-compared to the welldeveloped rift valley to the north and south-and also seems to be related to a transverse volcanic basement ridge (Fig. 3). Sample HLY0102-D36-1 (Profile 7; $49 \pm 34 \mathrm{ka}$ ) is located on a volcanic structure that straddles the active rift axis implying that it is a recent eruption (Fig. 3). Samples HLY0102-D35-12 (Profile 6; $1.31 \pm 0.03 \mathrm{Ma})$ and sample HLY0102-D35-20 (3.13 $\pm 0.09 \mathrm{Ma})$ 


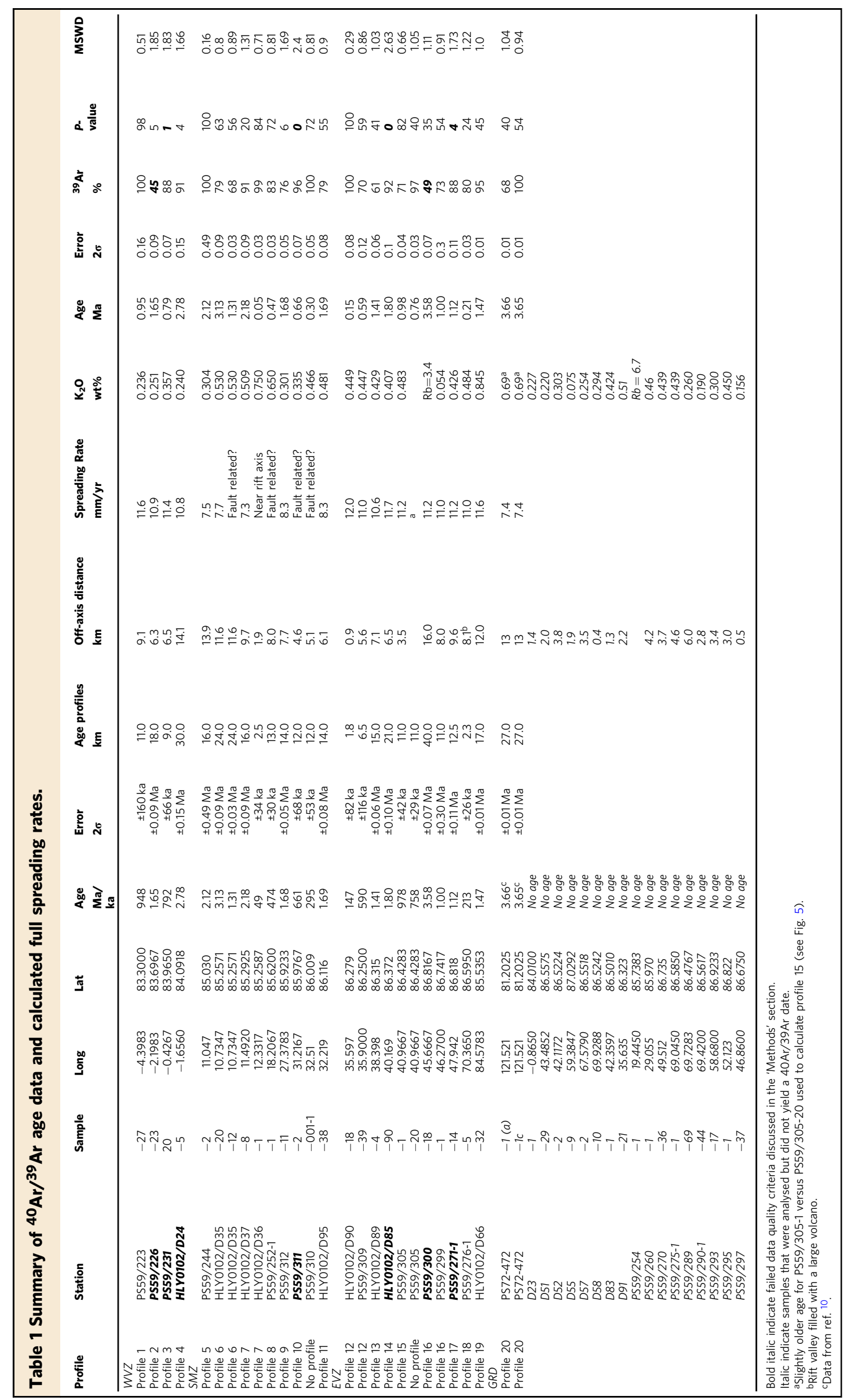



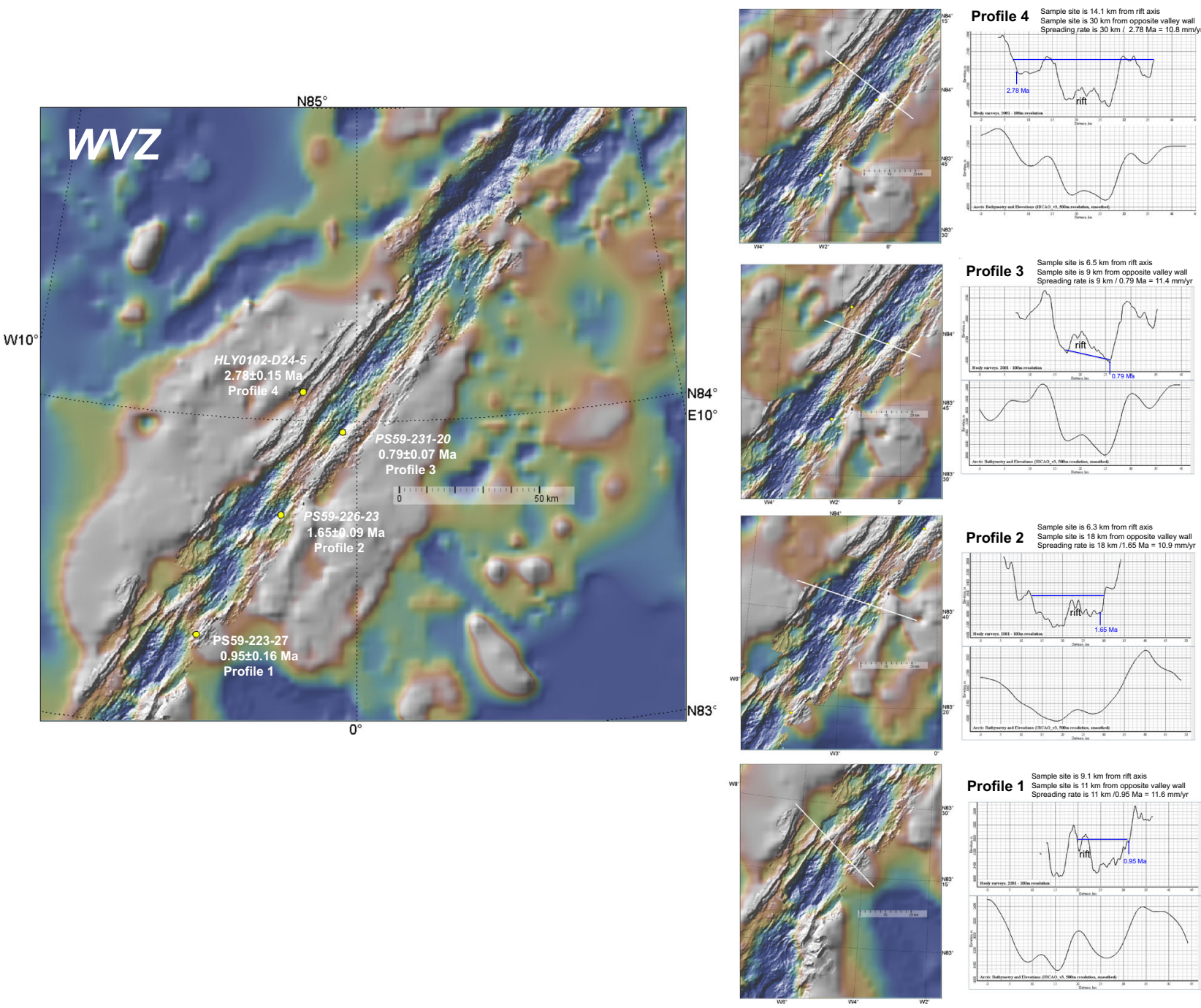

Fig. 2 Age-distance profiles in the WVZ. A large panel shows the locations of dredge samples and reported isotopic ages and an assigned age-distance profile number. The italicised sample labels are for dates that fail on the data quality criteria discussed in the 'Methods' section (Table 1). These individual profiles $(P)$ are shown on smaller bathymetric maps as white lines crossing the rift valley. The locations of dated dredge samples are indicated by yellow dots. Profile depths are based on high-resolution multibeam (100-m contour) data (top panel) and the lower resolution International Bathymetric Chart of the Arctic Ocean (IBCAO) ${ }^{56}$ (bottom panel). Shown also are the distances between dredge sites and the rift axis (labelled 'rift') and between the corresponding magmatic fragment on the opposite side of the rift, and the calculated full spreading rate (Table 1). Blue arrows are for the locations of dated samples along with depth profiles. P1 is orientated somewhat obliquely to the rift valley to connect the dating sample site with the corresponding fragment on the northern side of the rift. The fragment on the northern side is largely indistinguishable from the rift axis due to asymmetric spreading. The profile is orientated across this fragment where the axis and fragment can be distinguished at the same depth as the dated sample. P4 is slightly oblique to locate the flank of the opposite flank using available high-resolution multibeam data. P2 and P4 are located higher up in the flanks than the locations of the dated samples to take into account sloping rift valley walls. This location adjustment adds insignificant amounts to the length of the profiles and the calculated spreading rates $(<1 \mathrm{~km} ;<0.5 \mathrm{~mm} / \mathrm{yr})$. Map prepared in GeoMapApp (www.geomapapp.org).

are both from the same dredge haul located high up on the rift valley wall. All five young ages are evidence of a relatively lowvolume transverse volcanic basement ridge extending away from the rift valley. Thus, the five anomalously young SMZ ages seem to be related to low-relief volcanism that can erupt across the entire rift valley and in association with transverse volcanic basement ridges (Fig. 3). Furthermore, low volume SMZ volcanism could also represent the across-axis "wandering" of axial magmatism over time.

\section{Discussion}

In the magmatic WVZ and EVZ, much larger volcanic centres can fill the rift valley, and samples from their flanks are mostly expected to yield ages consistent with rifting at the rift axis, e.g., ref. ${ }^{1}$. But if these large volcanic centres are sampled at their base closer to the rift valley wall, they could potentially yield anomalously young ages for their location in the rift valley and corresponding to a wider zone of accretion that is typically found in amagmatic segments. Large volcanic structures might also evolve differently after rifting relative to the location of the more amagmatic and normal rift valley walls. As discussed in the 'Methods' section a potential source of uncertainty in calculating the spreading rate is whether one or both walls facing the rift axis is sloping and leading to a variation in the calculated spreading rate. For example, the increased elevation of the magmatic WVZ and EVZ might result in valley walls with shallower profiles compared to the amagmatic SMZ. This will increase the wall 


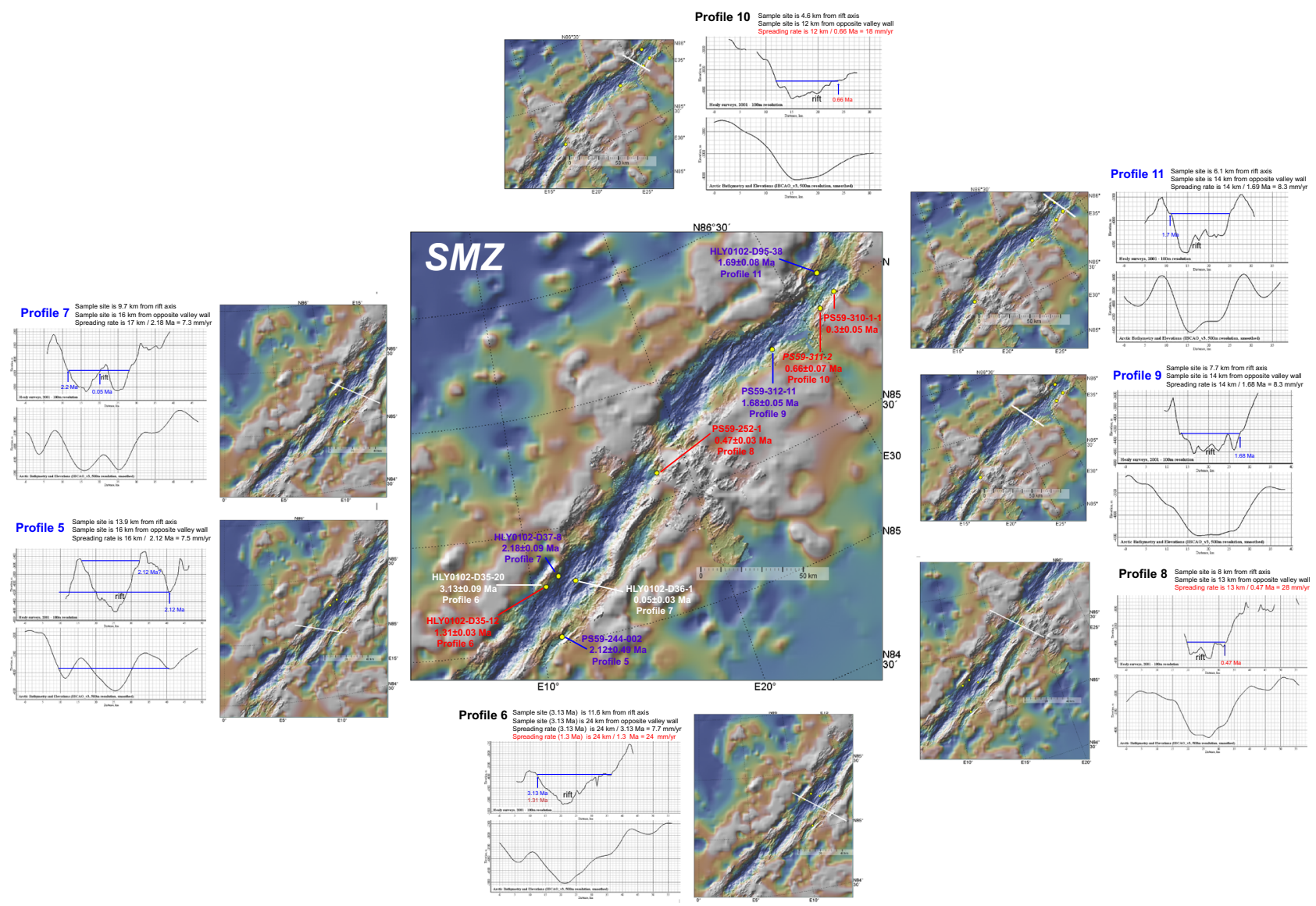

Fig. 3 Age-distance profiles in the SMZ. The SMZ is magma poor and magmatism can reach the surface away from the rift axis via large faults. P5 is oblique to the rift valley to connect the offset eastern tips of elongate fragments. A further complication is that the dredge sample was recovered on the side of a magmatic fragment facing away from the rift axis. Calculating the spreading rate from this location yields an anomalously fast-spreading rate of $\sim 15 \mathrm{~mm} / \mathrm{yr}$ compared to the rest of the profiles, particularly the nearby P6 and P7. The spreading rate is calculated from the crest of the fragment assuming that the dated sample reflects the age for the fragment as a whole. Red text is for samples from the valley walls yielding unrealistic young ages and spreading rates. For example, the dredge haul along P6 recovered basalts dated at 1.3 to $3.1 \mathrm{Ma}$. The anomalously young age is compatible with young basalts reflecting off-axis volcanism through faults. Blue text is for samples yielding coeval ages and matching spreading rates from opposite flanks at the southern (P5 \& P7) and northern (P9 \& P11) end of the SMZ. Other details as in Fig. 2.

separation for coeval rifted fragments leading to the calculation of a faster spreading rate. This mechanism might be expressed at the GRD by the inferred relationships between the spreading rate and the steepness of the valley walls (Fig. 5).

Alternatively, deep-reaching faults ${ }^{14}$ and/or jumps of the rift axis suggested by asymmetric spreading (Table 1) might act to keep the SMZ rift valley wall more vertical. At ultraslowspreading ridges, detachment faulting is thought to be a fundamental process in mantle rock exhumation and the generation of smooth seafloor ${ }^{14-16}$. In the case of the amagmatic SMZ, microearthquakes show that it lacks shallow seismicity in the upper $15 \mathrm{~km}$ of the lithosphere, but that it unusually produces earthquakes down to depths of $35 \mathrm{~km}^{14}$. This implies cold, thick lithosphere, with an upper aseismic zone that probably reflects substantial serpentinization of the upper lithosphere either along distinct, deep-reaching shear zones that concentrate strain or through pervasive alteration of at least $10 \%$ of the mantle rocks ${ }^{14}$. Evidence that in amagmatic regions of ultraslow-spreading ridges, serpentinization and fluid circulation may reach far deeper into the mantle than previously assumed is in line with less magmatism that isn't located so much along the central part of the axis but instead reflects a deeper and wider melting regime.

Next, we consider whether trends in our data correlate with published geophysical and geochemical data and attempt to understand the overall (regional) functioning of an ultraslow spreading ridge. More specifically, we are seeking a relationship between the new ${ }^{40} \mathrm{Ar} /{ }^{39} \mathrm{Ar}$ age data-especially the data that are inconsistent with spreading ages predicted by marine magnetic data-and the various unexpected findings arising from the AMORE expedition. A recent global shear wave velocity model $^{17}$ shows that temperature varies in the upper mantle beneath the Gakkel Ridge. The WVZ is located above a lowvelocity anomaly (Fig. 6) reflecting the presence of hotter asthenosphere at a depth of $150-80 \mathrm{~km}$ in the Eurasia Basin ${ }^{17}$ possibly due to mantle inflow from the North Atlantic ${ }^{9,17,18}$ According to this model, the EVZ is located above another seismic anomaly corresponding to hot asthenosphere at a depth of 200-150 km, which extends across the central Arctic from the Canada Basin to the Eurasia Basin (Fig. 6). The apparent agreement between the low-velocity anomalies and the boundaries of the magmatic and amagmatic segments is remarkable (Fig. 6). Moreover, they coincide better with an SMZ-EVZ boundary that we can infer from the differences in the average spreading rate and the style of crustal accretion, which is about $5^{\circ} \mathrm{E}$ east of initial estimates at $34^{\circ} \mathrm{E}^{1}$ (Fig. 6). But at shallower asthenospheric depths the low-velocity anomalies do not match the magmatic and amagmatic boundaries (Supplementary Figure 2). It is generally the case, however, that the details of 


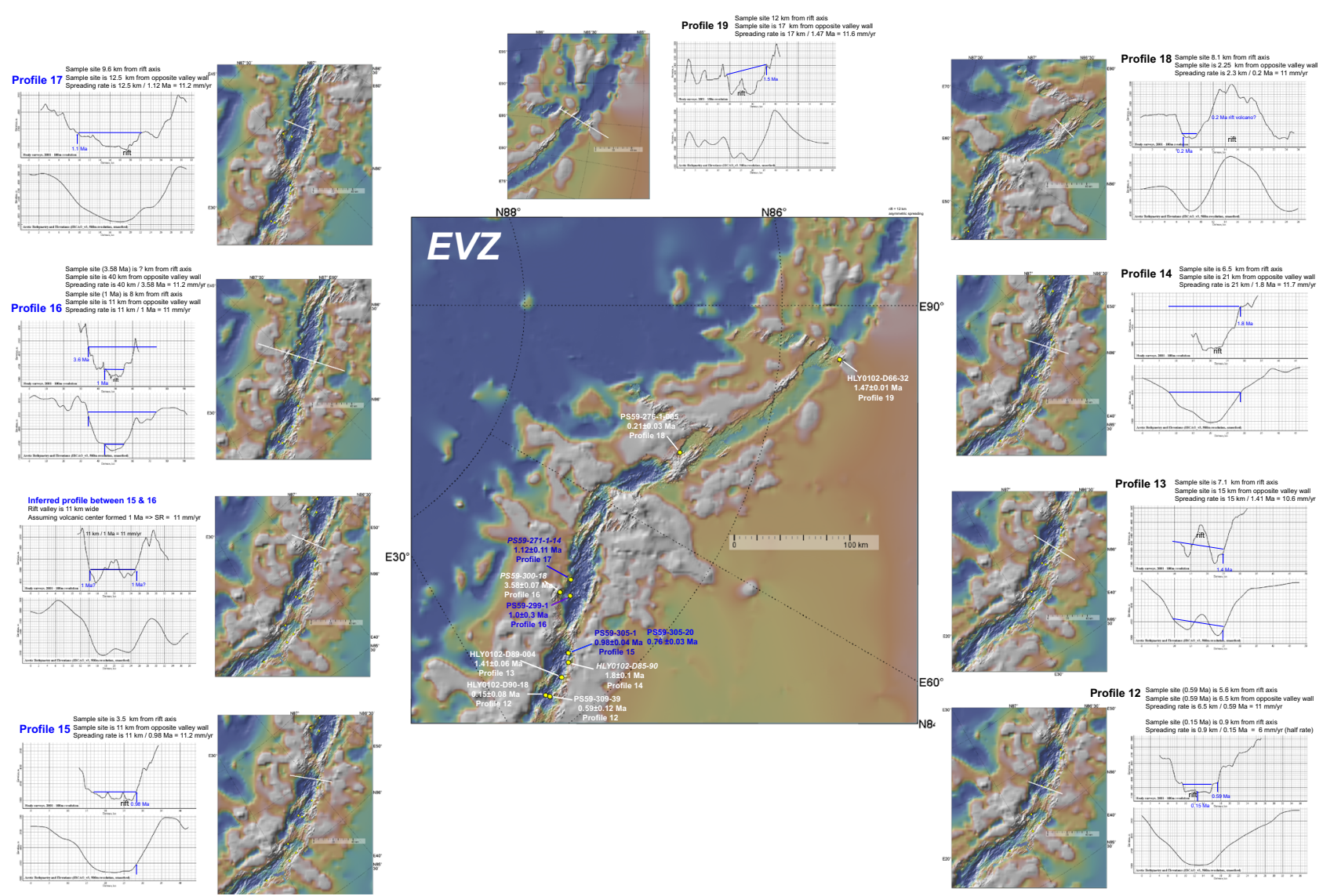

Fig. 4 Age-distance profiles in the EVZ. Blue text is for samples yielding coeval $\sim$ Ma ages and matching spreading rate from opposite flanks the southern (P15) and northern (P16 \& P17) flanks of the EVZ. These profiles bound a magmatic centre in the rift valley. A similar spreading rate can be inferred from this volcanism assuming that P15-P17 samples are from the same event. The process of successive cycles of volcanism and rifting discussed in the text is illustrated by P18 marking the early stage of dismemberment of a $0.2 \mathrm{Ma}$ large axial ridge-like volcano filling the rift valley and P19 crossing an older, already dismembered 1.5 Ma axial volcano. Other details as in Fig. 2.
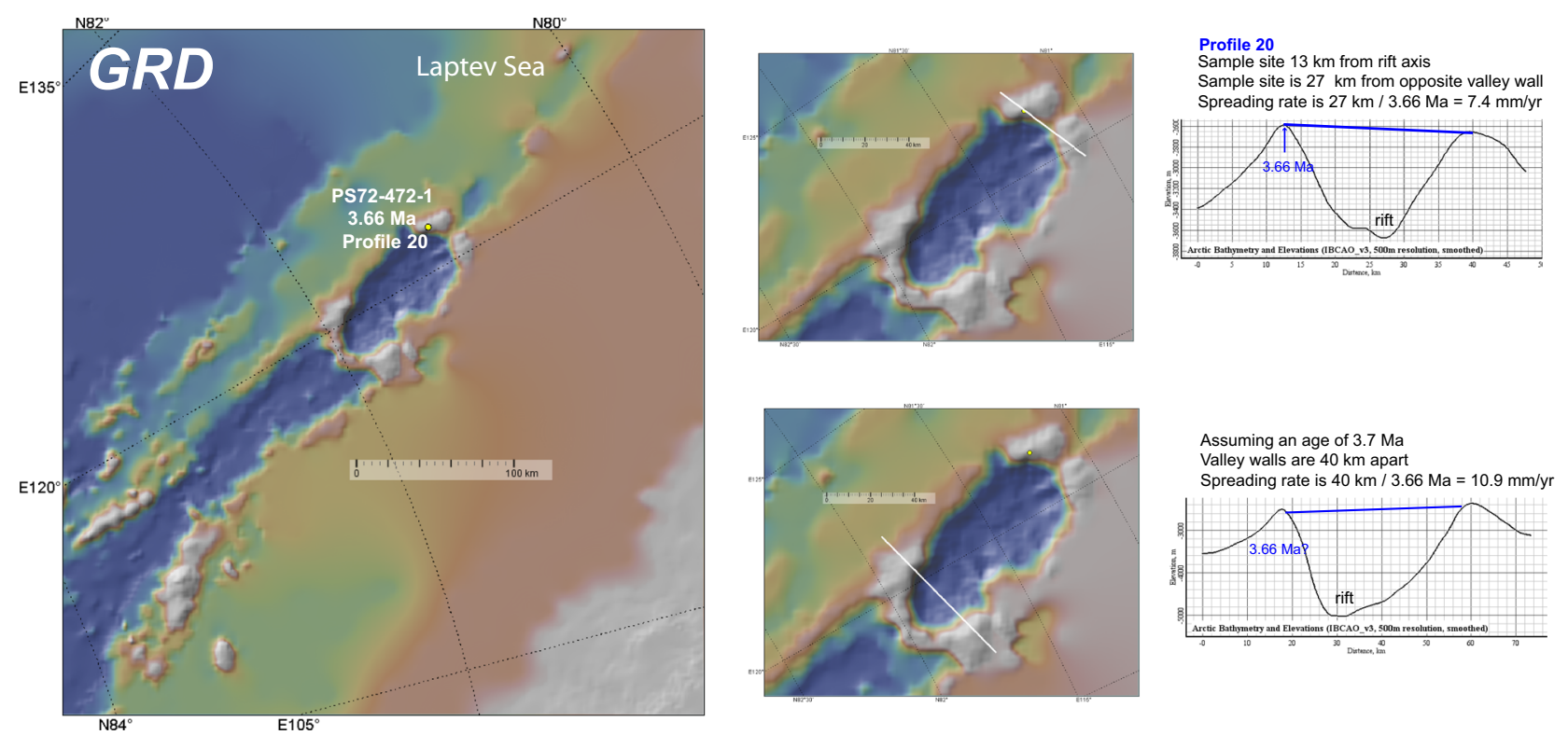

Fig. 5 Age-distance profile in the GRD. P20 predicts the dismemberment of a $3.7 \mathrm{Ma}^{10}$ axial volcano. Note that the wider rift valley to the west of P20 corresponds broadly with the width of the EVZ whereas the narrower rift valley east of P2O extends into the Laptev Sea. Furthermore, assuming that the volcanism on the flank of the wider axial valley at the western end of the GRD is also 3.7 Ma yields a faster EVZ-like spreading rate. Other details as in Fig. 2. 
A
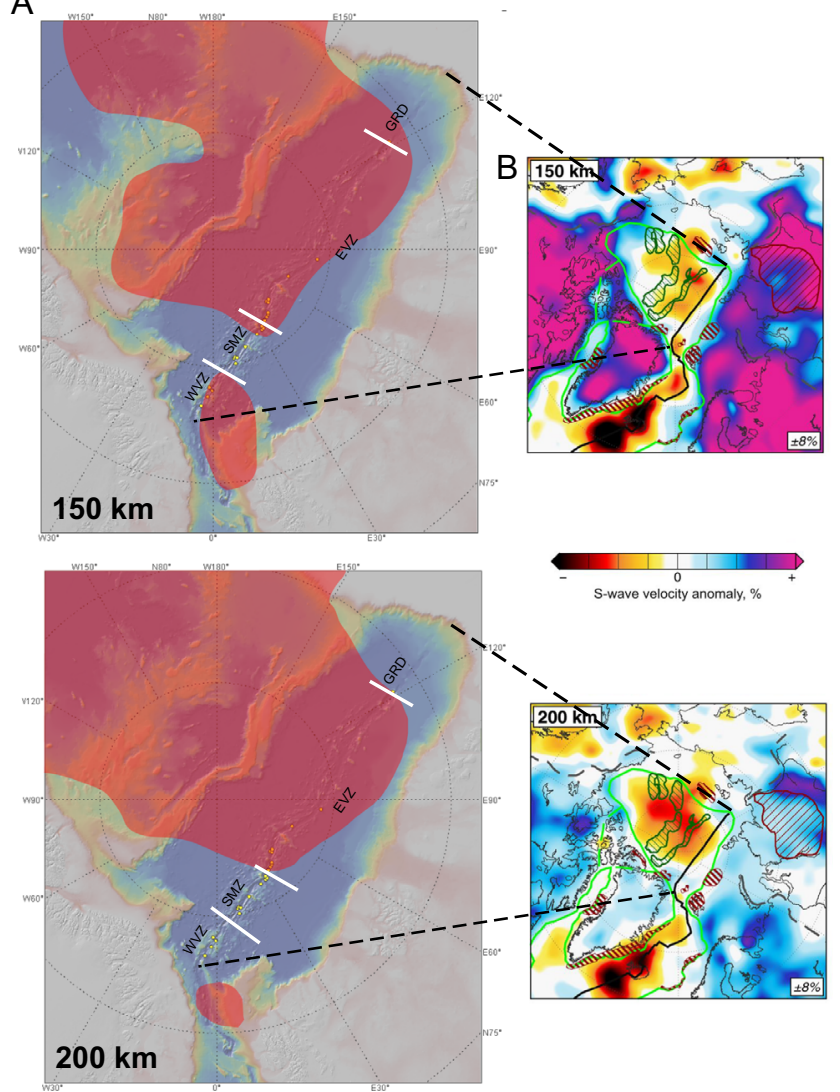

Fig. 6 The Gakkel Ridge volcanic zones and upper mantle low-velocity anomalies. A Relation between low-velocity anomalies at 200 and $150 \mathrm{~km}$ depth $^{17}$ and the different volcanic zones ${ }^{1}$ as defined by average spreading rates in Fig. 1. Note that the low-velocity anomaly extending across the central Arctic underlies the EVZ and the low-velocity anomaly extending from the North Atlantic is located under the WVZ. The SMZ and GRD lie between these low-velocity regions. B The AMISvArc tomographic model at 200 and $150 \mathrm{~km}$ from ref. ${ }^{17}$ and Supplementary Figure 2 show that these low-velocity anomalies do not extend to shallower depths. This tomographic model is a global, shear wave velocity model of the upper mantle and crust incorporating additional data from in and around the Arctic region ${ }^{17}$. Further details are available in ref. ${ }^{17}$.

(deeper) structures are better constrained by surface wave tomography. For example, the wavelength of the data in the referenced study is around $230 \mathrm{~km}(\mathrm{Vs}=4.62 \mathrm{~km} / \mathrm{s}, \mathrm{f}=50 \mathrm{~s})$ so the tomography model can only resolve structures of half of the wavelength $(\sim 120 \mathrm{~km})$. This is especially true in the central Arctic, where seismic stations are only located at the rim of the ocean basin. This low seismic station density limits even further the tomographic resolution and explains why the low-velocity anomalies do not match the WVZ, SMZ and EVZ boundaries at shallower mantle depths. Nevertheless, while there are potentially large errors in the tomography model for the shallow structure of the mantle under the ridge, it provides first-order information on the temperature below the Gakkel Ridge, which does correlate with our findings derived from the surface volcanism. We conclude therefore that there is a relation between a constant WVZ and EVZ spreading defined by ${ }^{40} \mathrm{Ar} /{ }^{39} \mathrm{Ar}$ dates and hotter regions in the mantle. We show also that this relationship breaks down above colder regions. Before this study, the assumption was that the spreading rate decreases steadily along the length of the ridge so ruling out the possibility of a relationship between spreading rate and mantle temperature.
A different study uses locally recorded microearthquakes to show that the lithosphere under amagmatic segments is much thicker $(\leq 40 \mathrm{~km})$ than below magmatic segments and only has a thin or absent oceanic crust ${ }^{2,3,19}$. Below the magmatic segments, the lithospheric thickness varies dramatically along-axis, thinning to as little as $15 \mathrm{~km}$ under volcanoes or sites of basalt exposure ${ }^{14,19}$. Thus, our ${ }^{40} \mathrm{Ar} /{ }^{39} \mathrm{Ar}$ dates reveal that spreading rate and accretion style correlates also with lithospheric thickness. Published geochemical data are also consistent with such a relationship. For example, a colder mantle leads to reduced melting as does a thicker lithosphere by creating a lid that inhibits asthenospheric upwelling, e.g., refs. ${ }^{20-24}$. In these situations, more fusible (enriched) components should be extracted preferentially with less dilution by liquids derived further up in the melting column $^{10}$ and references therein ${ }^{25}$. In the SMZ, low \% melting shown by the lack of magmatic activity is also evident from the chemistry of the basalts ${ }^{1}$ that exhibit a positive correlation between $\mathrm{Na}_{8.0}\left(\mathrm{Na}_{2} \mathrm{O}\right.$ normalized to $\left.8 \% \mathrm{MgO}\right)$ and depth as a proxy for $\%$ melting ${ }^{26,27}$. This is contrasted by the shallower WVZ that exhibit the lowest $\mathrm{Na}_{8.0}$ and the EVZ falling roughly in between the WVZ and SMZ1. The alkaline GRD sample (PS72/ $472-1$ ) is predicted to lie above the common $\mathrm{Na}_{8.0}$ range of the Gakkel Ridge (2.8-3.6 wt $\% \mathrm{Na}_{2} \mathrm{O}$ ) pointing toward lower degrees of mantle melting ${ }^{10}$. Trace element and isotopic data for the ridge also point to a greater proportion of more fusible components due to low extents of melting at the SMZ ${ }^{1}$ and GRD-LS segments ${ }^{10}$, consistent with thicker lithosphere ${ }^{14,19}$ and/or cooler mantle. In the amagmatic segments, any low-volume melts that get erupted may have been transported through the thickened lithosphere via faults, allowing for the transfer of uncontaminated low-volume melts of more fusible (fertile $\pm \mathrm{CO}_{2}$ ) mantle sources.

Radiogenic isotope ratios of $\mathrm{Sr}-\mathrm{Nd}-\mathrm{Pb}$ are not fractionated by magmatic processes and thus can help to more directly characterize the source(s) contributing to melts. $\mathrm{Sr}-\mathrm{Nd}-\mathrm{Pb}$ isotope ratios in WVZ lavas have a distinct isotopic signature (DUPAL ${ }^{28}$ ) considered to reflect contamination by thermally eroded subcontinental lithospheric mantle (SCLM $)^{18}$. Contamination by SCLM and/or subducted lithosphere ${ }^{29,30}$ might explain enhanced melting, e.g., ref. ${ }^{31}$ that is consistent with the somewhat shallower low-velocity anomaly beneath the WVZ (Fig. 6). Thus, the correspondence between the northern limit of the observed SCLMcontaminated low-velocity anomaly and the observed boundary between the WVZ and SMZ suggests that the inflowing hot mantle may have modified the character of WVZ seafloor spreading ${ }^{17,18}$. In the case of the less magmatic EVZ (compared to the $\mathrm{WVZ})^{1}, \mathrm{Sr}-\mathrm{Nd}-\mathrm{Pb}$ isotope ratios and highly incompatible element ratios show that the mantle does not have a distinct (e.g., DUPAL) isotopic signature ${ }^{10,32}$. In contrast, it is suggested that on a local scale the Arctic mantle contains low-melting fertile components, e.g., refs. $10,18,20$ and references therein ${ }^{32}$. Reference 32 modelled trace elements with mantle melting to find that geochemical variability in the EVZ can be explained by a heterogeneous mantle source composed of depleted MORB mantle plus a metasomatized mantle. Figure 7 shows that the maximum level of enrichment of this heterogenous EVZ mantle source increases systematically westward, roughly from the middle of the EVZ to the SMZ-WVZ boundary. In addition, we infer that the maximum level of source enrichment increases systematically eastwards toward the eastern boundary of the EVZ marked by the GRD (Fig. 7). We argue that this geochemical trend is more consistent with decreasing temperature than lithospheric thickness, particularly as geophysical studies show no evidence for a corresponding systematic thickening of the lithosphere ${ }^{14,19}$.

Finally, ref. 18 identify a compositional boundary between the WVZ and EVZ mantle sources within the SMZ, at around $14^{\circ} \mathrm{E}$ (Fig. 7). The Sr-Nd-Pb isotopic composition of SMZ samples on 

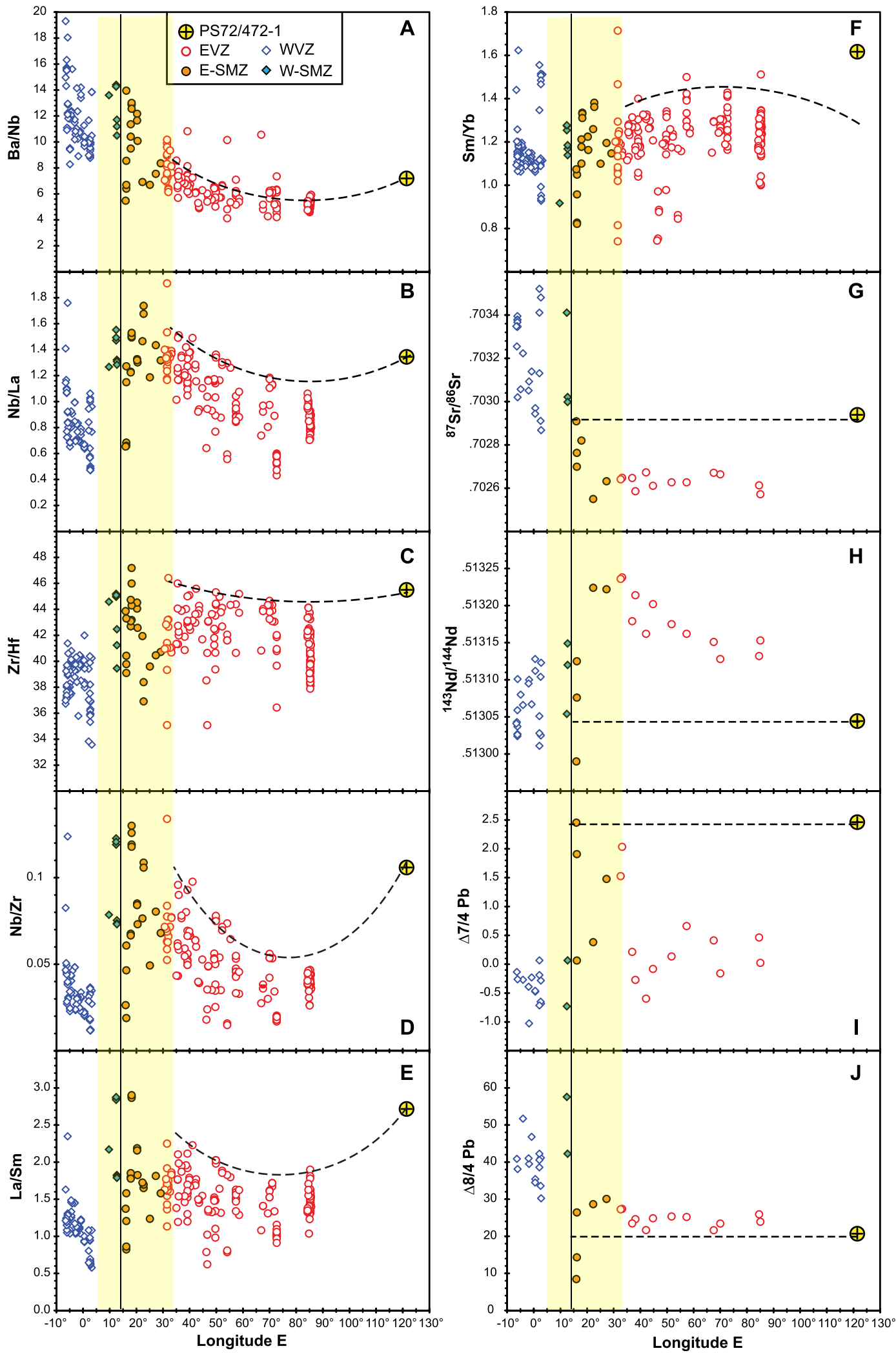

Fig. 7 Geochemical trends along the Gakkel Ridge. Along-axis variations of incompatible element ratios of $\mathbf{A ~ B a / N b , ~ B ~ N b / L a , ~ C ~ Z r / H f , ~ D ~ N b / Z r , ~ E ~ L a / S m , ~}$ and $\mathbf{F ~ S m} / \mathrm{Yb}$ in Gakkel lavas and long-axis variations of $\mathbf{G}{ }^{87} \mathrm{Sr} /{ }^{86} \mathrm{Sr}, \mathbf{H}^{143} \mathrm{Nd} /{ }^{144} \mathrm{Nd}$, and $\mathrm{Pb}$ isotopes expressed as $\mathbf{I} \Delta 7 / 4 \mathrm{~Pb}$ and $\mathbf{J} \Delta 8 / 4$. The Delta $(\Delta)$ notation reflects deviations from typical compositions of Pacific and Atlantic MORB on ${ }^{208} \mathrm{~Pb} /{ }^{204} \mathrm{~Pb}-{ }^{206} \mathrm{~Pb} /{ }^{204} \mathrm{~Pb}$ diagrams ${ }^{28}$. Note that the majority of Gakkel melts are tholeiitic, while alkaline melts are infrequent but occur in each segment ${ }^{10}$. The vertical line marks the isotopic boundary at $\sim 14^{\circ} \mathrm{E}^{18}$. The dashed line shows maximum incompatible element enrichment and variation in ${ }^{87} \mathrm{Sr} /{ }^{86} \mathrm{Sr},{ }^{143} \mathrm{Nd} /{ }^{144} \mathrm{Nd}$, and Pb isotopes discussed in the text. The figure is adapted from ref. ${ }^{10}$, their Fig. 5 and is based on published data of volcanic glasses (compilation of ref. ${ }^{58}$ ) and melt inclusions (refs. ${ }^{32,59}$ ) and a basalt sample from the GRD ${ }^{10}$. 
the EVZ side of this $14^{\circ} \mathrm{E}$ boundary increase to higher levels of enrichment compared to the rest of the EVZ, most clearly in $\Delta 7 / 4$ $\mathrm{Pb}$. This observation is consistent with a greater proportion of low-degree melts from the underlying DUPAL and EVZ mantle sources due to thicker lithosphere and/or cooler mantle. However, the transition from very thin to the thick crust at the SMZEVZ boundary ${ }^{14,19}$ is expected to have a spike in REE enrichment reflecting the thicker SMZ lid. The EVZ trace element geochemical trends are consistent with decreasing \% melting of a variably enriched (metasomatized) MORB (EVZ-type) source linked to a thermal anomaly that grades to cooler temperature away from roughly the middle of the EVZ at roughly $70-80^{\circ} \mathrm{E}$. In the more magmatic WVZ, geochemical trends are consistent with a thermal anomaly fed by DUPAL-like mantle inflowing from the North Atlantic ${ }^{18}$. In conclusion, adopting the interpretations of the most recent tomographic model for the Arctic published in 2017, we argue that our new ${ }^{40} \mathrm{Ar} /{ }^{39} \mathrm{Ar}$ data for the Gakkel Ridge shows that spreading rate and accretion style correlates with locations of thermochemical anomalies in the asthenosphere beneath the ridge. Evidence that the structure of the lithosphere, the extent of magmatism, and its composition correlate with spreading rate and style of accretion also links them in turn to mantle temperature.

Next, we consider how the temperature structure of the underlying mantle might be controlling variations in spreading rate and accretion style, composition, and thickness of the lithosphere (depth). Ridge-push and slab-pull are considered to be the processes responsible for driving spreading at ridges. Ridge-push is the result of gravitational forces acting on the young, raised oceanic lithosphere forming at ridges ${ }^{33}$. In plates without any subduction, such as the Arctic region, ridge-push might be the main or even the only force driving spreading and plate motion ${ }^{34,35}$. Thus, small changes in the temperature of the asthenosphere and, to a much lesser extent, composition due to thermochemical anomalies ${ }^{36}$, can lead to large variations in the volume of melts in the melting zone and the corresponding elevation of spreading ridges $26,27,37,38$. Heat at a ridge will also thin the lithosphere by weakening the lithosphere closer to the surface and elevating the depth boundary between the brittle lithosphere and the weaker, ductile asthenosphere ${ }^{39}$. For example, at the Gakkel Ridge, earthquakes show thinning of the lithosphere to $\leq 15 \mathrm{~km}$ below volcanoes (or sites of basalt exposure) in the magmatic sections, compared to thick lithosphere ( $\leq 40 \mathrm{~km}$ ) (with thin or absent oceanic crust $\left.{ }^{2,3}\right)$ below amagmatic sections ${ }^{14,19,40}$. Slightly increasing mantle temperatures (and a slight lowering of lateral densities) will also destabilise the normal thermal and compositional stratification leading to the development of gravitational instabilities or small-scale convection (SSC), e.g., refs. ${ }^{41,42}$. Ample observational data is showing that active (buoyant, three-dimensional, diapiric, episodic) mantle upwelling distinguishes slow-spreading ridges from intermediate- and fastspreading ridges ${ }^{4-49}$. Boundary-layer instabilities will further thin/erode the base of the cold, thick Arctic lithosphere ${ }^{14,19}$, especially under ultraslow moving lithosphere ${ }^{41,42}$. In summary, we argue here that hotter mantle associated with the low-velocity anomalies under the EVZ and WVZ leads to a thinner, more elevated lithosphere that increases the gravitational forces acting on the young, raised oceanic lithosphere.

On a global scale, variations in depths (uplift of the lithosphere) of the ocean ridges and lava composition are considered to reflect largely the temperature structure of the underlying mantle ${ }^{26,27}$. Gakkel is the deepest of the ocean ridges and provides a test of this global correlation and its origin ${ }^{50}$. Here we show that there is a relation between the temperature structure of the underlying mantle and ${ }^{40} \mathrm{Ar} /{ }^{39} \mathrm{Ar}$-defined spreading rates and accretion modes and by inference the thickness of the lithosphere (depth) and ridge geochemistry. We argue that this is evidence that the global relation between the depths of the ocean ridges, lava composition, and temperature ${ }^{26,27}$ is valid for most ridges. Moreover, it implies that global models can be expanded to include spreading rate and style of crustal accretion.

We have shown also that ${ }^{40} \mathrm{Ar} /{ }^{39} \mathrm{Ar}$ age data can robustly measure spreading rates along spreading centres, even along an ultraslow spreading ridge. Isotopically dating young, low potassium spreading ridge samples is now possible thanks to recent advances in high-resolution multi-collector mass spectrometry and sample preparation methods. The most significant original insight provided by these dates is that, together with the latest tomography model for the Arctic ${ }^{17}$, they show that steady spreading rate correlates with hotter regions in the underlying upper mantle. Whereas amagmatism reflects colder underlying upper mantle. Our findings imply that ultra-slow spreading is not necessarily a linear process with constantly decreasing spreading rates towards the rotation pole, as predicted by global models assuming rigid tectonic plates and extrapolation from older magnetic anomalies at the Gakkel Ridge. Rather, ultra-slow spreading is discontinuous with several segments acting independently from each other depending on the (changing) thermal structure under the ridge.

\section{Methods}

${ }^{40} \mathrm{Ar} /{ }^{39} \mathrm{Ar}$ dating of Gakkel Ridge samples. The groundmass samples were prepared following the methods of ref. ${ }^{51}$. The $200-180 \mu \mathrm{m}$ samples measured at Oregon State were cleaned in a series of hour-long acid baths, progressing from $1 \mathrm{~N}$ $\mathrm{HCl}$ to $6 \mathrm{~N} \mathrm{HCl}$ to $1 \mathrm{~N} \mathrm{HNO}_{3}$ to $3 \mathrm{~N} \mathrm{HNO}_{3}$, followed by a final milli-Q water bath. Each separate was picked by hand under a binocular microscope to ensure the removal of alteration, and to confirm the purity of the separate. Groundmass samples were irradiated for 6 hours in the CLICIT position at the Oregon State University TRIGA reactor. Incremental heating experiments were conducted for each sample. Irradiated samples were loaded into copper planchettes for analysis using a Thermo Scientific ARGUS-VI multi-collector mass spectrometer at the OSU Argon Geochronology Laboratory following the procedure described in ref. ${ }^{52}$. All ages are calculated relative to Fish Canyon Tuff (FCT) sanidine with an age of $28.201 \mathrm{Ma}^{53}$ and using the decay constants after ref. ${ }^{54}$. The correction factors for neutron interference reactions at the TRIGA are $(2.64 \pm 0.02) \times 10^{-4}$ for $\left({ }^{36} \mathrm{Ar} /{ }^{37} \mathrm{Ar}\right) \mathrm{Ca},(6.73 \pm 0.04) \times 10^{-4}$ for $\left({ }^{39} \mathrm{Ar} /{ }^{37} \mathrm{Ar}\right) \mathrm{Ca},(1.21 \pm 0.003) \times 10^{-2}$ for $\left({ }^{38} \mathrm{Ar} /{ }^{39} \mathrm{Ar}\right) \mathrm{K}$ and $(8.6 \pm 0.7) \times 10^{-4}$ for $\left({ }^{40} \mathrm{Ar}{ }^{39} \mathrm{Ar}\right) \mathrm{K}$. Ages were calculated using the ArArCALC v2.7.052 software of ref. ${ }^{55}$, with errors including uncertainties on the blank corrections, irradiation constants, J-curve, collector calibrations, mass fractionation, and the decay of ${ }^{37} \mathrm{Ar}$ and ${ }^{39} \mathrm{Ar}$.

The quality of an $\mathrm{Ar} /{ }^{39} \mathrm{Ar}$ step-heating experiment is assessed based on the following criteria: an acceptable age plateau (1) includes at least $50 \%$ of the gas released, (2) has a mean square weighted deviation (MSWD) of $\sim 1.0$ and within the statistically allowed upper limit, (3) shows an inverse isochron with a ${ }^{40} \mathrm{Ar} /{ }^{36} \mathrm{Ar}$ intercept of about $295.5 \pm 2 \sigma$, and (4) has a concordant plateau, isochron, and total fusion ages and (5) a $p$-value $>5 \%$. Seven samples have a plateau with $<50 \% 30 \mathrm{Ar}$ and/or a $p$-value $<5 \%$ (see Table 1 and Fig. 1). Full analytical results are available in Supplementary Dataset 2.

Calculation of spreading rates. Spreading rates are calculated using dated samples that have been dredged from magmatic structures that have been fragmented apart and transported away as seafloor spreads from the active central rift axis. Full spreading rates are calculated based on the separation distance between these magmatic fragments and measured isotopic ages: $\mathrm{SR}=$ distance $(\mathrm{km}) /$ age $(\mathrm{Ma})$

In an ideal scenario spreading rates should be calculated using isotopic ages for samples from in situ fragments of the same magmatic edifice located on the opposite sides of the rift axis and at the same depth. But the in situ location of dredged samples is not known reliably and the depths of dredged samples on the opposite side of the axis might be different. For example, basalt might have fallen from higher up in the rift valley wall, or flowed a significant distance vertically and/ or horizontally (parallel-to-spreading direction) after eruption. Dated samples are not available necessarily from directly opposite sides of the rift axis or fragments of the same magmatic edifice. In the case of the SMZ low volume of melts can reach the surface away from the rift axis via large faults at off-axis distances of up to $10-15 \mathrm{~km}$.

Magmatic fragments should be rifted completely and then transported orthogonally away from the rift axis by symmetric seafloor spreading. Asymmetric spreading is evident from a comparison of half spreading rates (samples site distances from the rift axis) and full spreading rates (age-distance profiles) (Table 1). This implies that rift zones might have migrated/jumped such that the rifts extend across a wide zone. Magmatic structures are not necessarily 
dismembered symmetrically or only partially. Moreover, young magmatic centres can be in the process of breaking apart.

Another consideration is that the walls of the rifted and transported magmatic fragments should be vertical. If one or both walls facing the rift axis is sloping due to, for example, up-faulting this will lead to vertical variation in the calculated spreading rate. In such cases calculating profile lengths from roughly the middle of the rift, walls can average out this effect.

Depth profiles across the ridge should be mapped completely by high-resolution multibeam (100-m contour) mapping rather than the much lower resolution International Bathymetric Chart of the Arctic Ocean (IBCAO) ${ }^{56}$. This is not always the case so depth profiles are sometimes oblique to the spreading ridge to identify and connect fragments on opposite sides of the rift axis.

But the main source of uncertainty that might bias systematically the calculation of spreading rates rises from the isotopic dates and the navigation of dredge positions and the length of the age profile. Using an assumed uncertainty of $0.5 \mathrm{~km}$ for the sample locations/age-profiles and the analytical uncertainty reported for the isotopic ages we have calculated the minimum and maximum spreading rates for each sample and then determined via linear regression a spreading rate of $11.1 \pm 0.9$ for $\mathrm{WVZ} / \mathrm{EVZ}$ and a rate of $7.6 \pm 0.5$ for SMZ/GRD .

In summary, due to the difficulty in quantifying the uncertainty for individual spreading rates we base our discussions and findings on the average spreading rates for the different ridge segments (Fig. 1)

\section{Data availability}

The authors declare that all the data for the ${ }^{40} \mathrm{Ar} /{ }^{39} \mathrm{Ar}$ age determinations and geochemical analyses supporting the findings of this study are available within the paper and its supplementary information files.

Received: 27 August 2020; Accepted: 15 October 2021; Published online: 29 November 2021

\section{References}

1. Michael, P. J. et al. Magmatic and amagmatic seafloor generation at the ultraslow-spreading Gakkel ridge, Arctic Ocean. Nature 423, 956-961 (2003).

2. Jokat, W. et al. Geophysical evidence for reduced melt production on the ultraslow Gakkel Ridge (Arctic Ocean). Nature 423, 962-965 (2003).

3. Jokat, W. \& Schmidt-Aursch, M. C. Geophysical characteristics of the ultraslow spreading Gakkel Ridge. Arct. Ocean. Geophys. J. Int. 168, 983-998 (2007).

4. Karasik, A. in Geophysical Methods of Prospects in Arctic, Leningrad, NIIGA, 5, 8-25 (in Russian) (1968)

5. Vogt, P. R., Taylor, P. T., Kovacs, L. C. \& Johnson, G. L. Detailed aeromagnetic investigations of the Arctic Basin. J. Geophys. Res. 84, 10711089 (1979).

6. Brozena, J. M. et al. New aerogeophysical study of the Eurasia Basin and Lomonosov Ridge: implications for basin development. Geology 31, 825-828 (2003).

7. Dick, H. J. B., Lin, J. \& Schouten, H. An ultraslow-spreading class of ocean ridge. Nature 426, 405-412 (2003).

8. Argus, D. F., Gordon, R. G. \& DeMets, C. Geologically current motion of 56 plates relative to the no-net-rotation reference frame. Geochem., Geophys., Geosyst. 12, Q11001 (2011).

9. Schmidt-Aursch, M. C. \& Jokat, W. 3D gravity modeling reveals off-axis crustal thickness variations along the western Gakkel Ridge (Arctic Ocean). Tectonophysics 691, 85-97 (2016).

10. Jokat, W., O'Connor, J., Hauff, F., Koppers, A. A. \& Miggins, D. Ultraslow spreading and volcanism at the eastern end of Gakkel Ridge, Arctic Ocean. Geochem. Geophy. Geosy. 20, 6033-6050 (2019).

11. Sauter, D., Whitechurch, H., Munchy, M. \& Humler, E. Periodicity in the accretion process on the Southeast Indian Ridge at $27^{\circ} 40^{\circ} \mathrm{S}$. Tectonophysics 195, 47-64 (1991).

12. Murton, B. J. \& Parson, L. M. Segmentation, volcanism and deformation of oblique spreading centers: a quantitative study of the Reykjanes Ridge. Tectonophysics 222, 237-257 (1993).

13. Mendel, V. et al. Magmato-tectonic cyclicity at the ultra-slow spreading Southwest Indian Ridge: evidence from variations of axial volcanic ridge morphology and abyssal hills pattern. Geochem. Geophys. Geosyst. 4, 9102 (2003).

14. Schlindwein, V., Demuth, A., Geissler, W. H. \& Jokat, W. Seismic gap beneath Logachev Seamount: an indicator for melt focusing a mid-ocean ridge? Geophys. Res. Lett. 40, 1703-1707 (2013).

15. Sauter, D. et al. Continuous exhumation of mantle-derived rocks at the Southwest Indian Ridge for 11 million years. Nat. Geosci. 6, 314-320 (2013).

16. Cannat, $M$. et al. Modes of seafloor generation at a melt-poor ultraslowspreading ridge. Geology 34, 605-608 (2006).
17. Lebedev, S., Schaeffer, A. J., Fuller, J. \& Pease, V. Seismic tomography of the Arctic region: inferences for the thermal structure and evolution of the lithosphere. Geol. Soc., Lond., Spec. Publ. 460, 419-440 (2017).

18. Goldstein, S. L. et al. Origin of a 'Southern Hemisphere' geochemical signature in the Arctic upper mantle. Nature 453, 89-93 (2008).

19. Schlindwein, V. \& Schmid, F. Mid-ocean-ridge seismicity reveals extreme types of ocean lithosphere. Nature 535, 276-279 (2016).

20. Langmuir, C. H. et al. Constraints from the Gakkel Ridge on the origin of MORB. Abstract 5.6.13, Goldschmidt, Copenhagen (2004).

21. Langmuir, C. H. \& Forsyth, D. W. Mantle melting beneath mid-ocean ridges. Oceanography 20, 78-89 (2007).

22. Niu, Y. L. \& O'Hara, M. J. Global correlations of ocean ridge basalt chemistry with axial depth: a new perspective. J. Pet. 49, 633-664 (2008).

23. Niu, Y. L. \& Hékinian, R. Spreading rate dependence of the extent of mantle melting beneath ocean ridges. Nature 385, 326-329 (1997).

24. Humphreys, E. R. \& Niu, Y. On the composition of ocean island basalts (OIB): the effects of lithospheric thickness variation and mantle metasomatism. Lithos 112, 118-136 (2009).

25. Reid, I. \& Jackson, H. R. Oceanic spreading rate and crustal thickness. Mar. Geophys. Res. 5, 165-172 (1981)

26. Klein, E. M. \& Langmuir, C. H. Global correlations ocean ridge basaltic chemistry with axial depth and crustal thickness. J. Geophys. Res. 92, 8089-8115 (1987).

27. Langmuir, C. H., Klein, E. M. \& Plank, T. in Mantle Flow and Melt Generation at Mid-Ocean Ridges (eds Morgan, J. P., Blackman, D. K. \& Sinton, J. M.) 183-280 (American Geophysical Union, 1992).

28. Hart, S. R. A large-scale isotope anomaly in the Southern Hemisphere mantle. Nature 309, 753-757 (1984).

29. Shephard, G. E., Trønnes, R. G., Spakman, W., Panet, I. \& Gaina, C. Evidence for slab material under Greenland and links to Cretaceous High Arctic magmatism. Geophys. Res. Lett. 43, 3717-3726 (2016).

30. Richter et al. An Early Cretaceous subduction-modified mantle underneath the ultraslow spreading Gakkel Ridge, Arctic Ocean. Sci. Adv. 6, eabb4340 (2020).

31. Dasgupta, R. \& Hirschmann, M. M. Melting in the Earth's deep upper mantle caused by carbon dioxide. Nature 440, 659-662 (2006).

32. Wanless, V. D., Behn, M. D., Shaw, A. M. \& Plank, T. Variations in melting dynamics and mantle compositions along the Eastern Volcanic Zone of the Gakkel Ridge: insights from olivine-hosted melt inclusions. Contrib. Mineral. Petrol. 167, 1005 (2014)

33. Turcotte, D. L. \& Schubert, G. Geodynamics (Cambridge University Press, 2002).

34. Richardson, R. M. \& Cox, B. L. Evolution of oceanic lithosphere: a driving force study of the Nazca Plate. J. Geophys. Res. 89, 10043-10052 (1984).

35. Stefanick, M. \& Jurdy, D. M. Stress observations and driving force models for the South American Plate. J. Geophys. Res. 97, 11905-11913 (1992).

36. Asimow, P. D. \& Langmuir, C. H. importance of water to oceanic mantle melting regimes. Nature 421, 815-820 (2003).

37. McKenzie, D. P. \& Bickel, M. The volume and composition of melt generated by extension of the lithosphere. J. Petrol. 29, 625-679 (1989).

38. White, R. S. Asthenospheric control on magmatism in the ocean basins. Geol. Soc., Lond., Spec. Publ. 42, 17-27 (1989).

39. DiVenere, V. Driving Forces of Plate Motions (Columbia University, Earth and Space Sciences, 2017)

40. Jokat, W., Kollofrath, J., Geissler, W. H. \& Jensen, L. Crustal thickness and earthquake distribution south of the Logachev Seamount, Knipovich Ridge. Geophys. Res. Lett. 39, L08302 (2012).

41. Ballmer, M. D., Ito, G., van Hunan, J. \& Tackley, P. J. Spatial and temporal variability in Hawaiian hotspot volcanism induced by small-scale convection. Nat. Geosci. 4, 457-460 (2011).

42. Agrusta, R. et al. Small-scale convection in a plume-fed low-viscosity layer beneath a moving plate. Geophys. J. Int. 194, 591-610 (2013).

43. Martinez, F., Hey, R. \& Höskuldsson. A. Reykjanes Ridge evolution: effects of plate kinematics, small-scale upper mantle convection, and a regional mantle gradient. Earth-Sci. Rev. 206, 102956 (2019).

44. Detrick, R. S., Needham, H. D. \& Renard, V. Gravity anomalies and crustal thickness variations along the Mid-Atlantic Ridge between $33^{\circ} \mathrm{N}$ and $40^{\circ} \mathrm{N} . J$ Geophys. Res. 100, 3767-3788 (1995).

45. Cannat, $M$. How thick is the magmatic crust at slow-spreading oceanic ridges? J. Geophys. Res. 101, 2847-2857 (1996).

46. Dunn, R. A., Lekić, V., Detrick, R. S. \& Toomey, D. R. Three-dimensional seismic structure of the Mid-Atlantic Ridge $\left(35^{\circ} \mathrm{N}\right)$ : evidence for focused melt supply and lower crustal dike injection. J. Geophys. Res. Solid Earth 110 (2005).

47. Niu, Y. \& Batiza, R. Magmatic processes at a slow-spreading ridge segment: 26오 Mid-Atlantic Ridge. J. Geophys. Res. 99, 19719-19740 (1994).

48. Phipps Morgan, J. \& Parmentier, E. M. Crenulated seafloor: evidence for spreading rate-dependent structure of mantle upwelling and melting beneath a mid-oceanic spreading center. Earth Planet. Sci. Lett. 129, $73-84$ (1995). 
49. Tolstoy, M., Harding, A. J. \& Orcutt, J. A. Crustal thickness on the MidAtlantic Ridge: Bull's-eye gravity anomalies and focused accretion. Science 262, 726 (1993).

50. Langmuir, C. H., Standish, J., Michael, P. \& Goldstein, S. Constraints on ocean ridge basalt generation from Gakkel Ridge basalts. Eos, Transactions, American Geophysical Union 87, Fall Meeting Supplement, Abstract V12c-01 (2006).

51. Koppers, A. A. P. et al. Limited latitudinal mantle plume motion for the Louisville hotspot. Nat. Geosci. 5, 911-917 (2012).

52. Konrad, K. et al. On the relative motions of long-lived Pacific Mantle Plumes. Nat. Commun. 9, 854 (2018).

53. Kuiper, K. F. et al. Synchronizing the rock clocks of Earth history. Science 320, 500-504 (2008).

54. Min, K. W., Mundil, R., Renne, P. R. \& Ludwig, K. R. A test for systematic errors in $\mathrm{Ar}-40 / \mathrm{Ar}-39$ geochronology through comparison with $\mathrm{U} / \mathrm{Pb}$ analysis of 1.1-Ga rhyolite. Geochim. Cosmochim. Acta 64, 63-98 (2000).

55. Koppers, A. A. P. ArArCALC-software for $40 \mathrm{Ar} / 39 \mathrm{Ar}$ age calculations. Comput. Geosci. 5, 605-619 (2002).

56. Jakobsson M. et al. The international bathymetric chart of the Arctic Ocean (IBCAO) Version 3.0. Geophys. Res. Lett. 39, https://doi.org/10.1029/ 2012GL052219 (2012).

57. Wessel, P., Smith, W. H. F., Scharroo, R., Luis, J. \& Wobbe, F. Generic mapping tools: improved version released. EOS Trans. AGU 94, 409-410 (2013).

58. Gale, A., Dalton, C. A., Langmuir, C. H., Su, Y. \& Schilling, J. -G. The mean composition of ocean ridge basalts. Geochem. Geophy. Geosy. 14, 489-518 (2013).

59. Shaw, A. M., Behn, M. D., Humphris, S. E., Sohn, R. A. \& Gregg, P. M. Deep pooling of low degree melts and volatile fluxes at the $85^{\circ} \mathrm{E}$ segment of the Gakkel Ridge: evidence from olivine-hosted melt inclusions and glasses. Earth Planet. Sci. Lett. Earth Planet. Sci. Lett. 289, 311-322 (2010).

\section{Acknowledgements}

P.J.M. acknowledges financial support from US National Science Foundation Grants OPP 9911795 and PLR 0425892 and the University of Tulsa McMan Endowment.

\section{Author contributions}

W.J. designed this project. P.J.M., W.J. and M.C.S. participated in the AMORE expedition. P.J.M. provided the sample material. D.P.M. and A.A.P.K. carried out the ${ }^{40} \mathrm{Ar} /{ }^{39} \mathrm{Ar}$ age determinations. M.C.S. produced Fig. 1 and helped J.M.O. calculate the spreading rates. J.M.O. wrote the original draft and all authors reviewed the manuscript and contributed to the discussion in this paper.

\section{Competing interests}

The authors declare no competing interests.

\section{Additional information}

Supplementary information The online version contains supplementary material available at https://doi.org/10.1038/s41467-021-27058-1.

Correspondence and requests for materials should be addressed to John M. O'Connor.

Peer review information Nature Communications thanks Fred Jourdan and the anonymous reviewer(s) for their contribution to the peer review of this work. Peer reviewer reports are available.

Reprints and permission information is available at http://www.nature.com/reprints

Publisher's note Springer Nature remains neutral with regard to jurisdictional claims in published maps and institutional affiliations.

(c) (i) Open Access This article is licensed under a Creative Commons Attribution 4.0 International License, which permits use, sharing, adaptation, distribution and reproduction in any medium or format, as long as you give appropriate credit to the original author(s) and the source, provide a link to the Creative Commons license, and indicate if changes were made. The images or other third party material in this article are included in the article's Creative Commons license, unless indicated otherwise in a credit line to the material. If material is not included in the article's Creative Commons license and your intended use is not permitted by statutory regulation or exceeds the permitted use, you will need to obtain permission directly from the copyright holder. To view a copy of this license, visit http://creativecommons.org/ licenses/by/4.0/.

(C) The Author(s) 2021 